\title{
Lived Experiences of Sex Life Difficulties in Men and Women with Early RA - The Swedish TIRA Project.
}

\author{
Gunnel Östlund, Mathilda Björk, Eva Valtersson and Annette Sverker
}

\section{Linköping University Post Print}

\section{Tweet}

N.B.: When citing this work, cite the original article.

Original Publication:

Gunnel Östlund, Mathilda Björk, Eva Valtersson and Annette Sverker, Lived Experiences of Sex Life Difficulties in Men and Women with Early RA - The Swedish TIRA Project., 2015, Musculoskeletal Care, (13), 4, 248-257.

http://dx.doi.org/10.1002/msc.1105

Copyright: Wiley: 12 months

http://eu.wiley.com/WileyCDA/

Postprint available at: Linköping University Electronic Press

http://urn.kb.se/resolve?urn=urn:nbn:se:liu:diva-126434 


\section{Lived experiences of sex life difficulties in men and women with early RA - The Swedish TIRA}

project.

Gunnel Östlund Associated professor ${ }^{1,}$ Mathilda Björk PhD ${ }^{2,3}$ Eva Valtersson ${ }^{4}$, Annette Sverker PhD ${ }^{4,5}$

${ }^{1}$ Department of Social Work, School of Health Care and Social Welfare, Mälardalen University, Sweden.

${ }^{2}$ Rehabilitation center, Department of Medical and Health Sciences, Linköping University, Sweden.

${ }^{3}$ Department of Rehabilitation, School of Health Sciences, Jönköping University, Sweden

${ }^{4}$ Department of Rehabilitation and Department of Medical and Health Sciences, Linköping University, Linköping, Sweden

${ }^{5}$ Faculty of Arts and Sciences, Department of Social and Welfare Studies, Social Work, Linköping University, Sweden.

Short title: Sex life in RA

Key words: sex life, patient perspective, rehabilitation, quality of life

\section{Corresponding author:}

Address for correspondence: Dr Annette Sverker Rehabilitation Section NSC, County Council of Östergötland 58185 Linköping, Sweden. E-mail: annette.sverker@regionostergotland.se ; annette.sverker@liu.se

Phone: 0046732702448 


\section{ABSTRACT}

Background: Women and men with rheumatoid arthritis (RA) experience restrictions in everyday life in spite of the development of new medications. Recent research has described in detail how participation limitations are experienced in everyday life from a patient perspective. However, knowledge of how sex and intimate relationships are affected is still scarce.

Objectives: The aim of this study was to explore sex life experiences in relation to sexual function and sexual relationships in women and men with early RA.

Methods: This study is part of the Swedish TIRA-project. The data collection includes 45 interviews with 24 women and 21 men, aged 20-63, which were recorded and transcribed verbatim. Critical Incident Technique was used to collect data, and content analysis to categorize the results.

Results: Half the participants stated that RA affected their sex life. The general descriptions formed five categories: sex life and tiredness, sex life and aging, emotional consequences of impaired sexual function, facilitators of sexual function and sexual relationships, and strain on the sexual relationship.

Conclusions: Sex life is still affected in early RA despite new effective treatment strategies. New strategies of communication, assessment and self-managing interventions concerning the sex life of patients with RA need to be implemented multi-professionally in health care. 


\section{BACKGROUND}

Rheumatoid Arthritis (RA) is a chronic, inflammatory disease that often leads to disability and reduced quality of life (Young et al., 2000; Birch and Bhattacharya, 2010). Over the past 20 years, treatment for persons with early RA has improved dramatically as a result of early interventions with disease modifying anti rheumatic drugs (DMARDs) and new biological medications (Furst et al., 2005). Nevertheless, a large number of persons with RA still report disabilities, often experienced as pain and fatigue, even early in the disease development (Lindén and Björklund, 2010)

In chronic diseases, just as in the general population, sex life satisfaction is an important factor for quality of life (Fugl-Meyer and Sjögren, 1999). However, where approximately a quarter of healthy adults consider themselves dissatisfied with their sex lives, more than two thirds of persons with RA experience a negative impact on their sex life (Kobolt et al., 2012). This negative impact has been described by both women and men with RA as reduced frequency of sexual intercourse, decreased desire, and decreased motivation to have intimate relationships (Palmer and El Miedany, 2011). The causes of this negative impact have previously been shown to be multi-faceted (Areskoug-Josefsson and Öberg, 2009), with clear differences between women and men (Palmer and El Miedany, 2011). The sex life of men with RA is more affected by physical issues, such as pain, fatigue, and joint mobility, whereas the sex life of women with RA is more affected by dryness of the mucous membranes caused by Sjogren's syndrome, psychological status, and desire (Frihka et al., 2011). Moreover, side effects from medications have been shown to affect sexual function, and incidences of impotence have been reported (Östensen, 2004). Whether these difficulties persist after today’s modern treatment with biological medications has not yet been studied.

A negatively affected sex life due to RA impacts the relationship with a partner, or potential partner, which often creates a mental burden for both patient and partner. According to Gutweniger (Gutweniger et al., 1999), the patient's burden is facilitated by communicating difficulties with their partner and thus eliminating the fear of being left or not understood, a fear that many persons with RA experience today. Sex life problems due to RA require open and adequate communication between the patient, possible 
relatives, and caregivers. However only 39\% of persons with RA feel comfortable addressing problems with their sex life at health visits (Hill et al., 2003), and health care professionals are also deficient in initiating discussion (Areskoug-Josefsson and Öberg, 2009).

A more detailed knowledge of how today's patients with early RA experience their sex life in order to facilitate discussion and subsequent interventions in health care is needed.

The aim of this study was to explore sex life experiences in women and men with early RA in relation to sexual function and sexual relationships.

Sexual function is defined as mental and physical functions related to the sexual act, and sexual relationship is defined as creating and maintaining a relationship of a sexual nature, with a spouse or other partner (World Health Organization, 2001).

\section{METHODS}

\section{Study design}

Critical incident technique (CIT) was the chosen method of data collection. CIT is described as a highly flexible qualitative research method that collects data on life experiences in defined situations (Flanagan, 1954). This study focused on describing experiences of sexual function and sexual relationships in women and men with early RA, but data were collected on all lived experiences of participation restriction in everyday life. CIT is closely linked to phenomenology as this qualitative theoretical methodology focus on describing subjective experiences (Dalhberg et al., 2008) and to capture the essence of how in this case the participants describe lived experience of intimate life.

The study was approved by the Research Ethics Committee of the Faculty of Health Sciences, Linkoping University, Sweden (Approval No.M168-05 T84-09). Informed consent was given by the participants.

\section{Participants}


This study is associated with the prospective multi-centre early arthritis project with the Swedish acronym TIRA-2 (Thyberg et al., 2012). The purpose of TIRA-2 was to establish clinical routines for early multiprofessional interventions at time for diagnosis, and to collect research data. A total of 522 patients fulfilling $\geq 4 / 7$ criteria as defined by the 1987 revised American College of Rheumatology Classification criteria (ACR-87) (Arnett et al., 1988), or at least morning stiffness for more than 60 minutes, symmetric arthritis and arthritis in the small joints were included in the Swedish early RA cohort (TIRA-2) between 2006-2009. Data regarding disease activity and disability was registered during regular follow-up appointments. Disease activity was assessed according to the 28-joint count disease activity score (DAS28) (Prevoo et al., 1995). Disability was reported using the Swedish version of the Health Assessment Questionnaire (HAQ) (Ekdahl et al., 1988). The patients were offered pharmacological interventions and multi-professional rehabilitative interventions based on individual needs.

Participants for the qualitative interview study were recruited from the TIRA-2 cohort. In addition to the TIRA-2 inclusion criteria, participants needed to be aged between 20-63 years and 3 years post RA diagnosis. The decision to include the participants three years after diagnosis was based on two aspects. First we wanted the patient to have enough time for adaption of living with RA and second we wanted to give the patient enough time to receive a well-adjusted RA medication before taking part in the interview study. Participation recruitment began in 2009 from the 128 participants included in TIRA-2 during 2006. Of these, 53 participants fulfilled the present study's inclusion criteria and were invited to take part. Eleven (8 women and 3 men) declined due to lack of time, no participation restrictions as a result of RA, or lack of interest in the study, leaving 42 participants. To increase the number of men in the study, 15 men from TIRA-2 who reached 3 years post-diagnosis in 2010 were invited, but four declined to participate due to lack of time or lack of interest. Further, the first six participants from TIRA-2 who reached their 3-year post-diagnosis in 2010 were invited. All these agreed to participate giving a total of 59 participants.

In 14 (10 women) of the 59 interviews; no information about sex life was collected since either the question about sex was not raised (10 interviews), or the participant did not give an answer (4 participants). 
Demographic and disease-related characteristics at the time of diagnosis of the 45 participants, with data collected about their sex life, are shown in Table 1.

-Insert table 1 about here

\section{Data collection}

The interviews were performed by the first, third and fourth authors (GÖ, EV, AS) who were not involved in the clinical treatment of the participants. A confidential interview location was chosen by each of the informants, either at home, the workplace, at the hospital or university. The interview questions were first pilot tested on five patients with RA to evaluate their functionality and to test the interview procedure. Then five patients were involved in testing the interview guide it also meant that they were involved in the development of the interview guide.After the pilot testing changes to the questions were made. The interviews were semi structured with open-ended questions about participation restriction related to RA in everyday life, using Critical incident technique (CIT) (Flanagan, 1954). CIT implies a consequent use of open-ended questions in order to permit the participants to respond in their own terms minimizing the imposition of predetermined responses. Interviews therefore started with questions such as: How is your everyday life? Can you describe an occasion in your everyday life, preferably during the last week, when you were hindered by or reminded of your RA? Follow-up questions allowed the patients to describe more about their situation or dilemma and the consequences of their dilemma (the interview guide is available upon request). The interview guide also included separate questions about intimate relations, including intimate life, which is analyzed in the present article: What effect do you think having RA has on your intimate and close relationships (sexuality)? Please tell us how you think they have been affected. This specific question was placed at the end of the interview guide to let the interviewer and the interviewee familiarize them with each, before other broaching a sensitive subject (the interview guide is available upon request). Interviews lasted between 45 and 90min, were digitally recorded with the patient's permission and transcribed verbatim. The data collection period was between October 2009 and May 2010.

\section{Analysis}


All 59 interviews were read and re-analysed in order to obtain information regarding sex life, and to check if a question on sex life was raised in all interviews (EV). Co-authors validated the analysis by reading through and re-analysing 10 of the interviews. The whole interview for each participant was read and transcribed verbatim in order to achieve both specific and contextual information. In 14 of the 59 interviews, participants gave no information about their sex life. Thus, 45 interviews were included in the results. The transcribed text containing information on sex life were abstracted, condensed and sorted into a table along with the original quotes. Preliminary categories were then formed from these contents (EV). These preliminary categories were checked and reformulated by the co-authors until consensus was reached. The content analysis used was inspired by qualitative research methods described by Patton (Patton, 2002).

\section{RESULTS}

The results describe lived experiences of sex lives in persons with early RA, i.e. sexual function and sexual relationships. From the interviews, 45 participants gave information on how RA affected their sex life (24 women and 21 men). The analysis found five major themes that characterized the lived experiences of sex life and early RA. Namely; sex life and tiredness, sex life and aging, emotional consequences of an impaired sexual function, facilitators of sexual function and sexual relationships and strain in the sexual relationships. Most of the participants lived in a heterosexual relationship at the time of the interview. Almost half the participants $(n=23)$ stated that RA did not affect their sex life and half $(\mathrm{n}=22)$ revealed that $\mathrm{RA}$ had a negative impact on their sex life.

Some of the participants did not experience any participation restrictions or impairments in their sex life at time of the interview, but described that their sex life had been affected when RA first appeared. However, three years after diagnosis they had found ways of adapting to their new situation. Some stated that time or medication had made a difference. Others described that they had learned to cope through open communication and finding new ways of handling the impairment or participation restrictions.

Gender similarities were found in the participants' descriptions of how they experienced their sex life to be affected. Generally, tiredness, which was experienced as a result of RA, affected sexual desire. 
Another general description concerned a changed sexual relationship, partly explained by aging, and partly by RA - two aspects which were hard to distinguish between. Moreover, some single participants described emotional consequences of impairments in sexual function, which were often explained as side effects of the medication Methotrexate. The participants also described management strategies and facilitating actions used to improve their sex life.

\section{Sex life and tiredness}

Several participants described how tiredness affected their sex life resulting in less time for, and interest in sexual activities. This change in desire was often accounted for or excused by other reasons. One man described how tiredness at a given moment overshadowed the desire for closeness earlier during the day and thus sex was postponed to another day.

"Yes you're tired. If, if it is, that, we come to this tiredness again then, for my part, I ... it really means that, many times then, when, early in the evening so you think then, this is comfortable, and so, like, you get close. But when you go to bed you are so tired and fall asleep.... Yes, lose interest in everything. Yes, it becomes nothing ... but it's not a big problem ... but the situation we're in now in our marriage, we can make up for it the next day." (male aged 53)

Lack of sexual interest and tiredness may or may not be related to RA. One participant suggested that a change in his relationship at the time, which resulted in the couple becoming more like friends than lovers, might explain his lack of sexual interest, though, he was unsure of RA s part in the changed sexual relationship. It is noteworthy that this participant is 26 years old.

” No, but it's not often then, ... there is also no real energy either. But we've been together a long time too. Where we've become more like friends, been together for nine years. ... No, I don't know what's the reason there."(male aged 26$)$ 
A woman described that she felt more tired and had to go to bed early every evening. She reflected that this tiredness could possibly be a side-effect of her medication. However, she argued that since she didn't consider herself as "sick", that conclusion was not particularly likely to be true.

"I believe that you possibly do get more tired and need to go to bed early at night and you might choose to get a good night's sleep instead (of having sex). Well, several of my medicines do list this as a side-effect saying that it can affect sexual desire, but that's hard to judge, I don't really know, I can't say, well, yes it is tiredness that affects me most... but I don't think my husband thinks like that, like he needs to take my illness into consideration, so it is the same thing there, because I don't feel that I am suffering from an illness he doesn't either need to treat me as being ill." (female aged 42)

\section{Sex life and aging}

A change in sex life may be due to aging rather than RA according to the participants. One woman stated that her sex life had been affected, but she wasn't sure if the problem was age-related or not.

"Then it was a bit tough for about, yeah if one says then about three, four years ago ... so it can have had an effect because it becomes of course that one doesn't hang out with others so much ... but that there, yes, I don't know, one can blame it on age too maybe... No, it's ok anyway ... it could well be that, many times like that one felt that, yes ... but it is ... nothing that we've had any concern over, no, neither [husband] or me, no, so it's been, yes, now you're just in it, in these tracks, the usual, yes...” (female aged 57)

When discussing their changed sex life, the uncertainty of how or whether RA had affected their sexual relationship was a common theme in the participants' answers. A question mark was often included in the participants' utterances. For example, the question mark is when the participants talk about changed sexual relationship, but don't know whether to blame RA or age. 
A young woman blamed her low libido on gender differences rather than RA. Most of the participants in a partnership gave two reasons as to why their sex life was affected, rather than just blaming RA.

“But men maybe want it a bit more often than women do and ... Yeah, I don't know how to solve it, it's most likely that I get what I want ... no but he is very understanding, I mean sure, I have to say, that it isn't so easy to understand every time maybe but, we have solved it, we simply have to agree ... Yes, so I can't say, this hasn't slowed me or slowed me down much” (female aged 28)

\section{Emotional consequences of an impaired sexual function}

RA, and sometimes the medication, caused reduced sexual arousal according to the participants. For those without a partner, these activity limitations had emotional consequences with many experiencing negative feelings such as grief and sadness, worry or anger. One woman recounted that the loss of sexual desire was a major grief in her life. A man talked about how his problems with sexual arousal made it difficult for him to handle intimate situations.

"I met a girl last year ... and I didn't damn well know how I was going to bring it up because I knew he wasn't working as well as he had before 'John Thomas' ... but it petered out ... because I explained to her that I had a bit of a problem with erections ... he's not dead.. it works of course but ... dammit” (male aged 47)

The female participants talked about how RA can make them feel unsexy and that sexual appearance and the sense of feeling sexy is part of becoming aroused, which is the first step towards having sex. Both married and single women brought up this problem.

"I can feel very, what shall I say, unsexy, when I can barely even walk, eh, and my hands especially, aren't particularly beautiful, because they have bumps and I can't move them so well back and forth" (female aged 22) 
None of the participants said that they had discussed this type of issue with health care professionals. One man was particularly upset by the lack of support in relation to sexual function and problems, since he had not received any questions on sexual issues from health care professionals at all.

"Not even a hint of a question on your sex life, on erections or anything. I think that's crap!" (male aged 47)

\section{Facilitators of sexual function and sexual relationships}

Several participants described how the medication Methotrexate affected erections and genital mucous. Some described how they refrained from certain medications or alcohol in order to be able performs sex, otherwise it would be impossible. One possible suggestion for enhancing sexual arousal and facilitating sexual activity was to adjust medication intake and plan to use 'drugs' only on days where sex was not possible.

The participants also described that it was necessary to find the best possible conditions to facilitate sexual arousal such as finding a suitable climate by going abroad to warmer countries. Moreover, body mobility is crucial when having sex according to the participants. One woman stressed the necessity to have a good back while others argued that body function without pain is necessary for wanting to have sex.

“In other words I have a lot of pain ... you don't think about being intimate then, not that day anyway ... except I think it's important, on the other hand I think it's important with closeness, hugs, in other words that you, eh, that you kiss and hug but it can stop there, you don't have to go further ... sure, I can have pain then, when I go to bed I can have pain even then, so I mean sure, it limits me ... it's probably not the first thing you think about when you have sex with someone, if you have pain I mean" (female aged 28) 
According to the above-cited woman, saying no to sexual intercourse does not include saying no to sexual relationships and being close. Women and men also described that certain days are worse than others for RA pain, which according to them limited the possible days for having sex.

"[sex life] is limited sometimes ... sometimes it works well and sometimes it doesn't work at all, when I have pain it doesn't work and then, unfortunately, that's what's a bit annoying with it, she thinks [the wife] then, amongst other things" (male aged 53)

Several men described that they found it particularly difficult to handle hand pain. One man described that finger pain complicated sexual relationships, but hand pain also fluctuated during the day. Thus pain consideration included choosing the right time of the day to be able to have sex.

”... she knows I have pain in my hands so that she can't have... can't take at any rate, you know ... Especially if you're lying and hugging, then your hands can get squeezed, you know. And that can really hurt. I'm more sore at night than ... because I've been busy and maybe worked, so maybe I'm more sensitive than in the mornings” (male aged 60)

Hand pain might complicate sexual relationships since it makes it impossible to act according to masculinity norms - staying on top.

"The ability to ... be the way you want to be gets worse ... to use your hands in the way you want to sometimes ... I can't lean on my hands ... wrists ... it doesn't work” (male aged 53)

\section{Strain on the sexual relationship}

Some participants described how RA affected their relationship negatively. Living with a person who needs help in everyday life situations or is in need of socio-emotional support may put extra pressure on the relationship. One man described how he felt like a failure not being able to validate his wife's needs. 
$" . .$. and I get tired and difficult when I'm with her ... you have to try and be considerate all the same, show that ... but she always looks at me when I'm in pain ... but then she thinks I'm not enough maybe, all the time ... if we're sitting and hugging and feeling good, then I don't want to do it, then I'd rather pull ... away or, more accurately, push her away, unfortunately ... I'm a failure. That's why I think she doesn't always accept the disease, but it's just how it is ... I think that's the hardest thing right now, that you can't validate your wife when she maybe needs it , ... but that's always something you have to work on ... as long as you have rheumatism anyway.” (male aged 53)

Some of the participants described having worries of being rejected due to their partner not being able to endure living with a person with disability long-term. They also expressed worry about not being good enough as a partner or that their partner would misinterpret their actions.

"Especially I think mentally ... and you can feel really bad and you think yeah but, think if this continues, that I'm going to ... feel like this and I'm going to look like this, is he going to accept me then because sex is a big part of a relationship ... I think it, eh, affects it a lot, and as I said, then it's how you feel on and off too ... yes, it's [fear] that he's going to leave me and then I'll be sad and have low self esteem also then, it leaves a mark, now I haven't been in a situation where it really has been a disaster, luckily, because I think it really would be, something that would sit emotionally for both of us I think, that the other one would maybe be, yeah but as my boyfriend then he'd be a little like this, a-ha, how is this actually going to work, will she be able to have sex with me in two years ... that's how I feel ... odd.” (female aged 22)

Open communication, compassion and understanding were, according to the participants' descriptions, necessary components in keeping up the closeness in the relationship. Living with RA not only includes the person affected, but also those close to them.

\section{DISCUSSION}


This study collected experiences of sex lives of people with early RA. Half the participants experienced impairment and/or participation restrictions in their sex life. Similar studies investigating experiences of patients with early RA are scarce. However a study by Karlsson (Karlsson et al., 2006) found that patients with early RA were less satisfied with life as a whole and with self-care, work and sex life compared with a reference group. In addition, two years after their RA diagnosis, the majority of men and women were not satisfied with their sex life. Patients with early RA, though, were more satisfied with most aspects of their lives compared with patients with long-standing RA (Karlsson et al., 2006). Pouchot (Pouchet et al., 2007) found that RA had a negative impact on sexuality (51\%) and intimate relationships (44\%). Kobelt (Kobolt et al., 2012), in agreement, found that more than two thirds of patients with RA felt their disease was an obstacle to sexual relationships, while in contrast only a third of the healthy control group reported facing obstacles to their sexual relationships. One study reported that in a healthy adult population, $47 \%$ of Swedish women and 23\% of men reported having one or more sexual problems (Fugl-Meyer and Sjögren, 1999), illustrating that in comparison, persons with RA experience sex problems more often than their healthy adult counterparts. Half the participants in the present study did not experience any problems in their sex life three years after diagnosis, even if they had problems when first diagnosed with RA.

\section{The hindrance of age and tiredness on sex life}

In the present study, age was experienced as being related to sex life problems, and it was discussed as to whether RA was also responsible. This was also addressed in the literature by Helland et al (Helland et al., 2011), and Abdel-Nasser (Abdel-Nasser and Essam, 2006). Kobelt (Kobelt et al., 2012) reported that sexual problems in persons with RA were associated with age. On the contrary, Hill (Hill et al., 2003) found that aging had no impact on the importance the patient placed on sexual ability. Van Berlo (Van Berlo et al., 2007) stated, in line with some of the participants in the present study, that RA patients do not differ from healthy controls regarding sexual dysfunction, indicating that a high percentage of individuals of comparable age experience sexual problems regardless of RA. Tiredness was also identified as being related to sex life problems among the participants. Tiredness, or fatigue, is still present among today’s RA patients with access to biological medications (Feldthusen et al., 2013) and is one important factor affecting the sex life of men and women with RA (Areskoug-Josefsson and Öberg, 
2009; Areskoug-Josefsson and Gard, 2010; Elst et al., 1984; Hellande et al., 2008), often in combination with pain (Frihka et al., 200; Gutweniger et al., 1999). According to Helland (Helland et al., 2008), fatigue was the symptom regarded as having the greatest impact on sex life. Even though many informants stated that the new biological drugs resulted in disease improvement, this improvement did not necessarily translate into an improved sex life, primarily due to continued fatigue.

\section{Emotional consequences of sexual impairment}

Emotional consequences of restrictions on sex life due to RA-related impairments included negative feelings such as grief and sadness, worry or anger according to the participants. Emotions resulting from living with RA have earlier been expressed in relation to life activities (Östlund et al., 2014) in both women and men. According to Yilmaz (Yilmaz et al., 2012), a detrimentally affected sex life was linked to depressive symptoms, while Helland et al (Helland et al., 2008) found similar connections, but with anxiety and distress. The participants in the present study mentioned grief and shame due to sexual impairment. Grief and shame are emotions that, to our knowledge, have not previously been mentioned specifically in relation to sex life in RA patients, but have been described as consequences of participation restrictions in everyday life (Östlund et al., 2014). The impact of negative factors on sex life is not limited to RA patients, as healthy individuals also weigh such negative and positive factors in their lives (Fugl-Meyer and Sjögren , 1999; Palmer and Miedany, 2011; Yilmaz et al., 2012).

\section{Strain on the sexual relationship}

Some participants stated that problems with their sex life affected their relationship. Hill (Hill et al., 2003) found from the results of a qualitative study that 23 of 41 participants (56\%) did not believe RA had changed their relationship with their partner in any way, but 18 (44\%) did. Reasons for sexual difficulties found in the study by Hill et al (Hill et al., 2003) were pain, fatigue, dry vagina, and difficulty finding comfortable sex positions, reduced sexual interest, and lack of spontaneity in relation to having sex. Activity limitations and reasons for lack of sexual participation were also seen in the present study. Participants experienced being unable to feel attractive when their wrists, fingers or legs no longer 
functioned as well as they previously had. It was also found that RA contributed to a strain on relationships, or for single persons, emotional consequences such as feeling vulnerable and insecure about how to handle sex with a new date. According to the participants, RA may not be visible in public, but in the bedroom, negative consequences due to medication or activity limitations were hard to hide.

\section{Suggested management strategies for sex life difficulties from a patient perspective}

The participants mentioned different ways of handling sexual function and sexual relationship problems, such as finding the best possible conditions to facilitate sexual arousal

or how to handle hand pain. This is in line with the self-management strategies described by Helland et al (Helland et al., 2008) which include postponing sexual activity until flares had passed; ignoring restrictions; adapting positions and movements; using alternative locations, painkillers, or pillows; initiating less strenuous sexual activity; having sex despite a lack of desire; and being creative during the sexual act. In clinical care of patients with RA, it has been suggested that self-management strategies be included in the multi-professional interventions (Stoffer et al., 2014). In the present study as well as in earlier research (National Rheumatoid Arthritis Society, 2013), patients stated that health care does not include assessments or interventions related to sex life. According to Matheson (Matheson et al., 2010), it is important to include the partner when managing RA in order to provide comprehensive supportive care for patients and their families. To achieve this we need to use assessment tools focusing on sex life difficulties in persons with RA in clinical follow-ups (Rosen et al., 2000; Gossec et al., 201236) by offering the patient and their partner sexual counseling.

\section{Methodological considerations}

In our qualitative study, approximately half the participants experienced that RA impacted their sex life negatively. However, the degree of impact was not questioned. The participants chose what they wanted to reveal about their sex life at the time of the interview. This needs to be kept in mind when evaluating the results. Information concerning sex life is often difficult to receive. Age and gender seemed to affect how comfortable the participants were with talking about sex in the interview. Younger participants 
talked about their sex life more easily, and older patients implied rather than spelled out detailed information. Two men raised the topic of sex as a problem early in the interviews, while other participants waited until sex was formulated as a specific question by the interviewer in the last past of the interview. Fourteen participants' comments on their sex life were missing. Some had not received a question with the word 'sex' included. The interviewers may have felt a little embarrassed bringing the subject up, or had interpreted the participant as being particularly uncomfortable when approaching the question of sex. Questionnaires where neither participants nor interviewers need to verbalise intimate questions, thus avoiding potential embarrassment, may be more suitable for collecting data on sex life. The use of questionnaires with follow-up interviews, if preferred by the participants, has been suggested by Gutweniger (Gutweniger et al., 1999).

\section{CONCLUSION AND CLINICAL IMPLICATIONS}

The present study shows that sex life is still affected by RA early in the disease process even after new biological medications, which result in many patients experiencing less disability, have been introduced. These expressed sex life difficulties highlight the need for structured assessment and interventions in order to help reduce problems in sexual function and sexual relationships. Since self-management has been raised as an important issue in the rehabilitation of rheumatic diseases (Stoffer at al., 2014; Hewlett et al., 2005), new strategies of communication, assessment and interventions concerning sex life in persons with RA need to be implemented in health care. One method of evaluating whether a patient experiences problems related to their sex life is to use a questionnaire such as the Valued Life Activity scale (Björk et al., 2013), where intimate relationships are addressed as one of 33 life activities, and then followed up by interventions from the multi-professional team.

In conclusion, this study demonstrates the importance of health care seriously incorporating issues concerning sexual function and sexual relationships in the rehabilitation of today's contemporarily treated RA-patients.

\section{ACKNOWLEDGMENTS}


The authors would like to thank research partner Birgitta Stenström, for valuable comments on the data analysis and results. The Swedish Rheumatism Association supported this work. 


\section{REFERENCES}

1. Abdel-Nasser AM, Essam AI. Determinants of sexual disability and dissatisfaction in female patients with rheumatoid arthritis. Clin Rheumatol. 2006; 25(6): 822-30.

2. Areskoug-Josefsson K, Öberg U (2009). A literature review of the sexual health of women with Rheumatoid Arthritis. Musculoskeletal Care. 2009;7(4): 219-26.

3. Areskoug - Josefsson K, Gard G. Women's experiences of sexual health when living with Rheumatoid Arthritis - am explorative qualitative study. BMC Musculoskelet Disord 2010; 15; 11:240-7.

4. Arnett FC, Edworthy SM, Bloch DA, McShane DJ, Fries JF, Cooper NS, Healey LA, Kaplan SR, Liang MH, Luthra HS. The American Rheumatism Association 1987 revised criteria for the classification of rheumatoid arthritis. Arthritis Rheum. 1988;31(3):315-24.

5. Birch JT, Jr., Bhattacharya S. Emerging trends in diagnosis and treatment of rheumatoid arthritis. Prim Care 2010; 37(4): 779-92, vii.

6. Björk M, Thyberg M, Waltersson E, Stenström B, Katz P (2013) Valued Life Activities: Swedish Version (VLA-SWE) with Cultural Adaptation, ICF Linkage and Psychometric Testing. Ann Rheum Dis 2013;72 Suppl 3:785.

7. Dahlberg K, Dahlberg H, Nyström M. Reflective Lifeworld Research. Lund: Studentlitteratur; 2008.

8. El Miedany Y, El Gaatary M, El Aroussy N, Youssef S, Ahmed I. Sexual dysfunction in Rheumatoid Arthritis patients: Arthritis and beyond. Clin Rheumatol 2012; 31(4): 601-6.

9. Elst P, Sybesma T, van der Stadt RJ, Prins APA, Hissink Muller W, den Butter A. Sexual problems in Rheumatoid Arthritis and Ankylosing Spondylitis. Arthritis Rheum1984; 27(2): 217-220.

10. Ekdahl C, Eberhardt K, Andersson SI, Svensson B. Assessing disability in patients with rheumatoid arthritis. Use of a Swedish version of the Stanford Health Assessment Questionnaire. Scand J Rheumatol. 1988;17(4):263-71. 
11. Feldthusen C, Björk M, Forsblad-d’Elia H, Mannerkopi K. Perception, consequences, communication, and strategies for handling fatigue in persons with rheumatoid arthritis of working-age-a focus group study. Clin Rheumatol 2013; 32(5): 557-566.

12. Flanagan C. The critical incident technique. Psychol Bull 1954; 51:327-358.

13. Frihka F, Maazoun F, Ben Salah R, Snoussi M, Masmoudi J, Nabil Mhiri, M, Bahloul Z. “Sexual dysfunction of married women with (drabbade av) Rheumatoid Arthritis” Dysfonction sexuelle chez femmes marries atteintes de polyarthrite rhumatoide. La Presse Médicale 2011; 40:e 521-e27. French

14. Fugl-Meyer AR, Sjögren K. Sexual disabilities and satisfaction in 18-74 year old Swedes. Scandinavian Journal of Sexology 1999; 2:79-105.

15. Furst DE, Breedveld FC, Kalden JR, Smolen JS, Burmester GR, Bijlsma JW, Dougados M, Emery P, Keystone EC, Klareskog L, Mease PJ. Updated consensus statement on biological agents, specifically tumour necrosis factor alpha\} (TNF $\{$ alpha\}) blocking agents and interleukin-1 receptor antagonist (IL-1ra), for the treatment of rheumatic diseases, Ann Rheum Dis. 2005,64 Suppl 4:iv2-14.

16. Gossec L, Solano C, Paternotte S, Beauvis C, von Krause G, Sordet C, Perdriger A. Elaboration and validation of a questionnaire ( Qualisex) to assess the impact of rheumatoid arthritis on sexuality with patient involvement. Clin Exp Rheumatol 2012; 30(4) :505-13.

17. Gutweniger S, Kopp M, Mur E, Gunther V. Body image of women with rheumatoid arthritis. Clin Exp Rheumatol 1999; 17:413-7.

18. Helland Y, Dagfinrud H, Kvien TK. Perceived influence of health status on sexual activity in RA patients: associations with demographic and disease related variables. Scand J Rheumatol 2008; 37:(3) 194-199.

19. Helland Y, Kjeken I, Steen E, Kvien T, Hauge MI, Dagfinrud H. Rheumatic Diseases and Sexuality: Disease Impact and Self-Management Strategies. Arthritis Care Res (Hoboken) 2011(63); 5:743-50.

20. Hewlett S, Cockshott Z, Byron M, Kitchen K, Tipler S, Pope D, Hehir M. Patients’ perceptions of fatigue in Rheumatoid Arthritis: Overwhelming, uncontrollable, ignored. Arthritis Rheum 2005; 53(5): 697-702. 
21. Hill J, Bird H, Thorpe R. Effects of rheumatoid arthritis on sexual activity and relationships. Rheumatology (Oxford) 2003; 42:280-6.

22. Kobelt G, Texier-Richard B, Mimoun S, Woronoff AS, Bertholon DR, Perdriger A, Maugars Y, Combe B. Rheumatoid arthritis and sexuality: A patient survey in France. BMC Musculoskelet Disord 2012; 10; 13:170-7.

23. Karlsson B, Berglin E, Wållberg-Jonsson S. Life satisfaction in early rheumatoid arthritis. A prospective study. Scand J Occup Ther. 2006; 13:193-9.

24. Lindén C, Björklund A. Living with rheumatoid arthritis and experiencing everyday life with TNF- $\alpha$ blockers. Scand J Occup Ther. 2010; 17(4): 326-34.

25. Matheson L, Harcourt D, Hewlett S. 'Your whole life, your whole world, it changes': Partners' experiences of living with Rheumatoid Arthritis. Musculoskeletal. Care 2010; 8(1): 46-54.

26. National Rheumatoid Arthritis Society. Emotions, relationships and sexuality. 2013. http://www.nras.org.uk/

27. Palmer D, El Miedany Y. Sexual dysfunction in rheumatoid arthritis: a hot but sensitive issue. $\mathrm{Br}$ J Nurs. 2011; 20(17): 1134-7.

28. Patton M Q (2002) Qualitative Research and Evaluation Methods. London: Sage.

29. Pouchot J, Le Parc JM, Queffelec L, Sichère P, Flinois A. Perceptions in 7700 patients with rheumatoid arthritis compared to their families and physicians. Joint Bone Spine 2007; 74(6): $622-6$.

30. Prevoo ML, van 't Hof MA, Kuper HH, van Leeuwen MA, van de Putte LB, van Riel PL. Modified disease activity scores that include twenty-eight-joint counts. Development and validation in a prospective longitudinal study of patients with rheumatoid arthritis. Arthritis Rheum 1995;38(1):44-8.

31. Rosen R, Brown C, Leiblum S, Meston C, Shabsigh R, Ferguson D, D'Agostino R Jr. The Female Sexual Function Index(FSFI):A Multidimensional Self-Report Instrument for the Assessment of Female Sexual Function. J Sex Marital Ther 2000;26(2):191-208.

32. Stoffer MA, Smolen JS, Woolf A, Ambrozic A, Bosworth A, Carmona L, Fialka-Moser V, Loza E, Olejnik P, Petersson IF, Uhlig T, Stamm TA; eumusc.net-working group. Development of 
patient centred standards of care for rheumatoid arthritis in Europe: the eumusc.net project. Ann Rheum Dis 2014; 73(5): 902-5

33. Thyberg I, Dahlstrom O, Björk M, Arvidsson P, Thyberg M. Potential of the HAQ score as clinical indicator suggesting comprehensive multidisciplinary assessments: the Swedish TIRA cohort 8 years after diagnosis of RA. Clin Rheumatol 2012; 31(5):775-83.

34. Van Berlo WTM, van de Wiel HBM, Taal E,Rasker WCM, Schutz W, van Rijswijk MH (2007). Sexual functioning of people with Rheumatoid Arthritis: a multicenter study. Clin Rheumatol 2007; 26 (1): 30-8.

35. World Health Organization. ICF: international classification of functioning, disability and health. WHO. 2001. Geneva.

36. Yilmaz H, Demir Polat HA, Yilmaz SD, Erkin G, Kucuksen S, Salli A, Ugurlu H. Evaluation of sexual dysfunction in women with Rheumatoid Arthritis: A controlled study. Sex Med 2012; 9(10): 2664-2670.

37. Young A, Dixey J, Cox N, Davies P, Devlin J, Emery P, Gallivan S, Gough A, James D, Prouse P, Williams P, Winfield J.How does functional disability in early rheumatoid arthritis (RA) affect patients and their lives? Results of 5 years of follow-up in 732 patients from the Early RA Study (ERAS). Rheumatology (Oxford) 2000; 39(6): 603-11.

38. Östensen M. New insights in to sexual functioning and fertility in rheumatic diseases. Best Pract Res Clin Rheumatol 2004; 18(2): 219-32.

39. Östlund G, Björk M, Thyberg I, Thyberg M, Valtersson E, Stenström B, Sverker A.(2014). Emotions related to participation restrictions as experienced by participants with early rheumatoid arthritis: A qualitative interview study (The Swedish TIRA project) Clin Rheumatol 2014; 33(10): 1403-13. 


\section{Corresponding author:}

Address for correspondence: Dr Annette Sverker Rehabilitation Section NSC, County Council of Östergötland 58185 Linköping, Sweden. E-mail: Annette.sverker@regionostergotland.se ; annette.sverker@liu.se

Phone: 0046732702448

Table 1. Participant group characteristics of the 45 participants, with data collected about their sex life

\begin{tabular}{lc}
\hline Variable & $\mathrm{n}=45$ \\
\hline Personal factors & \\
Sex, n (\%) women & $24(53)$ \\
n (\%) men & $21(47)$ \\
Age, years mean (sd) & $52(11)$ \\
Disease-related factors & $2.6(1.4)$ \\
DAS28 mean (sd) & $0.4(0.5)$ \\
HAQ mean (sd) & $41(91)$ \\
DMARDs, n (\%) ongoing medication & \\
\hline n=number, mean=mean value, sd=standard deviation, DAS28= Disease Activity Score, HAQ= Health \\
Assessment Questionnaire, DMARDs= Disease Modifying Anti-rheumatic Drugs including biologic medication.
\end{tabular}

